\title{
Suture granuloma masquerading as primary ovarian malignancy: a case report
}

\author{
Seetu Palo ${ }^{1 *}$, Kanchana P. V. N. ${ }^{2}$ \\ ${ }^{1}$ Department of Pathology, Andaman and Nicobar Islands Institute of Medical Sciences, Port Blair, Andaman and \\ Nicobar, India \\ ${ }^{2}$ Department of Pathology, Maharajah’s Institute of Medical Sciences, Vizianagram, Andhra Pradesh, India
}

Received: 18 October 2019

Accepted: 15 November 2019

*Correspondence:

Dr. Seetu Palo,

E-mail: seetu.pearl@gmail.com

Copyright: ( $)$ the author(s), publisher and licensee Medip Academy. This is an open-access article distributed under the terms of the Creative Commons Attribution Non-Commercial License, which permits unrestricted non-commercial use, distribution, and reproduction in any medium, provided the original work is properly cited.

\begin{abstract}
Suture granuloma is an uncommon surgical complication comprising of foreign body granulomatous tissue reaction against the suture material. We present a case of ovarian suture granulomas in a 28 -year-old female who was clinicoradiologically misdiagnosed as ovarian carcinoma. She presented with intermittent pelvic pain, on and off low-grade fever and menstrual irregularities for 6 months and had undergone laparoscopic tubectomy two years back. Ultrasonographic findings were suspicious of left ovarian malignancy. CA-125 levels were elevated (115 U/mL). Left oophoro-salpingectomy was performed and histopathological examination revealed multiple suture-related granulomas.
\end{abstract}

Keywords: Malignancy, Ovary, Suture granuloma

\section{INTRODUCTION}

The formation of suture granuloma is an uncommon condition post-surgery. Both absorbable and nonabsorbable suture material can elicit such response and it usually tends to develop in early post-operative period. ${ }^{1}$ Here, authors report an unusual case of ovarian suture granuloma which simulated as a primary ovarian malignancy.

\section{CASE REPORT}

A 28-year-old female presented to the gynaecology outpatient department with the chief complaints of intermittent pelvic pain, on and off low-grade fever and menstrual irregularities for 6 months. She had undergone laparoscopic tubectomy two years back at a private centre. However, the medical records pertaining to it were not available with the patient. General physical and systemic examination as well as routine laboratory tests were within normal limits. Ultrasonography (USG) of the abdomen showed an echogenecitically complex solidcystic lesion of the left adnexa, suspicious of malignancy. A serum CA-125 test was ordered which was elevated to $115 \mathrm{U} / \mathrm{mL}$ (normal range 0 to $35 \mathrm{U} / \mathrm{mL}$ ). With a provisional diagnosis of ovarian malignancy, an exploratory laparotomy was undertaken which revealed left tubo-ovarian mass with no other suspicious lesion. Left oophoro-salpingectomy was performed and the specimen was sent for histopathological examination. Grossly, the tubo-ovarian mass measured $8 \times 6 \times 4 \mathrm{~cm}$. External surface was bosselated and congested. The fallopian tube was stretched over and adherent to the ovarian mass. Fimbrial end could not be identified. Cut section showed variegated appearance with ill-defined, solid, grey-white areas and interspersed cystic areas filled with mucoid material (Figure 1). Multiple sections from appropriate areas were processed. Histopathological 
study revealed multiple foreign body (suture)-related granulomatous reaction comprising of foreign body type giant cells, histiocytes, dense mixed inflammatory cell infiltrate and areas of fibrosis (Figure 2). The cystic areas were consistent with benign follicular cysts. Normal ovarian parenchyma was not found, grossly as well as microscopically. The fallopian tube showed features of chronic salpingitis. There was no evidence of malignancy. The patient's postoperative course was uneventful, and on one-year follow-up, she was healthy with no fresh complaints. Her follow-up CA-125 levels were within normal limits.

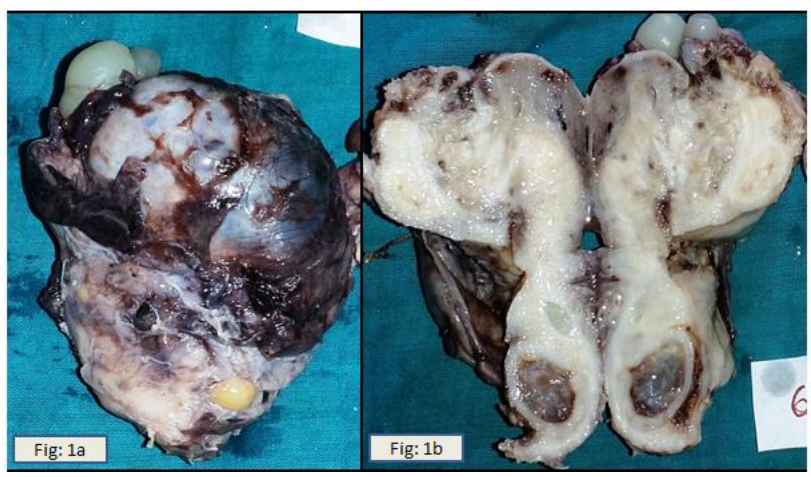

Figure 1: External (1a) and cut surface (1b) of the tubo-ovarian mass displaying solid and cystic appearance with mucoid areas.

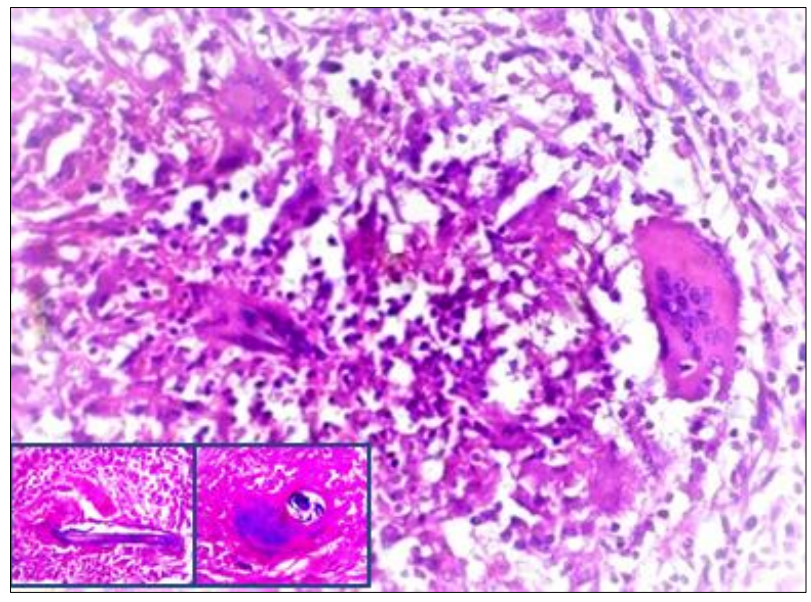

Figure 2: Granulomatous reaction comprising of many foreign body type giant cells with inset showing engulfed suture material.

\section{DISCUSSION}

Ovarian granulomas are relatively uncommon. Tuberculosis is the most common etiology of ovarian granulomatous inflammation. However, in a study of 32 ovarian granulomas in Northern Ireland over a 13-year period, the most common cause of ovarian granulomas (n = 15) was foreign body reaction to suture material. ${ }^{2}$ Suture granulomas can develop anywhere in the body, post-surgery. Eldridge et al, reported almost all suture granulomas to develop within two years of surgery and they concluded that the time gap between the operation and the formation of suture granuloma can provide a clue to the diagnosis. ${ }^{3}$ On the contrary, it can also present after a prolonged time interval. Takeshita $\mathrm{N}$ et al, reported a case of pelvic suture granuloma in a 61-year-old female with a prior history of total hysterectomy for uterine myoma 16 years back and caesarean delivery 35 years back. ${ }^{4}$ In this case, suture granuloma developed two years after the surgery. Authors opine that the inflammatory reaction is initiated in the early post-operative phase in all cases, but patients may become symptomatic after a variable time period.

Radiologically, suture granulomas can be mistaken as either primary malignancy or tumour recurrence in a surgically treated case of cancer. ${ }^{1,4-8}$ Rettenbacher et al, stated that suture granulomas would characteristically appear as hypoechoic lesion with hyperechoic single or double lines on USG. ${ }^{9}$ But, most of the cases lack specific USG findings, like in this case. Even, 18F-FDG PET is fraught with false-positive results. ${ }^{4-8}$ de Sousa Leão and colleagues suggested that the specificity of $18 \mathrm{~F}$ FDG PET increases, when its findings are interpreted in conjunction with levels of serum tumor markers. ${ }^{5}$ In the present case, CA-125, a marker of ovarian malignancy, was raised, but not markedly raised as in most cases of ovarian malignancy. Nevertheless, a definite diagnosis can be made after only after histopathological examination. Fine needle aspiration cytology can also prove helpful in establishing the diagnosis. ${ }^{7,10}$

\section{CONCLUSION}

Suture granuloma is clinically important and every effort should be made to diagnose it correctly because it can potentially mimic as malignancy, both clinically as well as radiologically, leading to unnecessary aggressive therapeutic interventions and further complications. Preoperative FNAC or intra-operative frozen section analysis can be of immense help.

\section{Funding: No funding sources \\ Conflict of interest: None declared \\ Ethical approval: No required}

\section{REFERENCES}

1. Sharma S, Kalyan S. Intra-abdominal suture granulomas masquerading as colon carcinoma: a case report. Adv Cytol Pathol. 2018;3(4):98-101.

2. McCluggage WG, Allen DC. Ovarian granulomas: a report of 32 cases. J Clin Pathol. 1997;50:324-7.

3. Eldridge PR, Wheeler MH. Stitch granulomata after thyroid surgery. Br J Surg. 1987;74:62.

4. Takeshita N, Tohma T, Miyauchi H, Suzuki K, Nishimori T, Ohira G, et al. Suture granuloma with false-positive findings on FDG-PET/CT resected via laparoscopic surgery. Int Surg. 2015;100:604-7. 
5. De Sousa Leão G, Mororó GT, De Carvalho AMC, Normando SRC, Vieira SC. FDG-PET/CT-positive foreign body granuloma mimicking colon cancer recurrence: case report. J Neoplasm. 2017;2(3):15.

6. Martínez-Martínez A, García-Espinosa J. Nonabsorbable suture granuloma mimicking a retroperitoneal metastatic implant in a patient with sigmoid neoplasm. Rev Esp Enferm Dig. 2016;108(9):579-80.

7. Chung YE, Kim EK, Kim MJ, Yun M, Hong SW. Suture granuloma mimicking recurrent thyroid carcinoma on ultrasonography. Yonsei Med J. 2006;47(5):748-51.

8. Imperiale L, Marchetti C, Salerno L, Iadarola R, Bracchi C, Vertechy L, et al. Nonabsorbable suture granuloma mimicking ovarian cancer recurrence at combined positron emission tomography/computed tomography evaluation: a case report. J Med Case Reports. 2014;8:202.
9. Rettenbacher $\mathrm{T}$, Macheiner $\mathrm{P}$, Hollerweger $\mathrm{A}$, Gritzmann N, Weismann C, Todoroff B. Suture granulomas: sonography enables a correct preoperative diagnosis. Ultrasound Med Biol. 2001;27:343-50.

10. Titton RL, Gervais DA, Boland GW, Maher MM, Mueller PR. Sonography and sonographically guided fine-needle aspiration biopsy of the thyroid gland: indications and techniques, pearls and pitfalls. AJR Am J Roentgenol 2003;181:267-71.

Cite this article as: Palo S, Kanchana PVN. Suture granuloma masquerading as primary ovarian malignancy: a case report. Int J Reprod Contracept Obstet Gynecol 2020;9:418-20. 